\title{
Introduction
}

\section{SECOND FLORENCE FERENCZI ISSUE}

\author{
Endre Koritar ${ }^{1}$
}

\section{BIRTHING NEW IDEAS}

The 13th International Ferenczi Conference, held in Florence, Italy, was a forum where scholars from different disciplines: psychoanalysts, psychiatrists, counselors, academics, psycho-historians, artists, writers-representing different orientations: classical, interpersonal, relational, object-relations, the Frankfurt School, and social sciences perspectives-connected in dialogues that bridged ideological gaps often resulting in the birth of new ideas and ways of thinking about and working with clinical phenomena. The impressive caesura of birth was experienced in the various discussion groups penetrated and impregnated with papers which had incubated in the minds of authors over three years since the last such meeting in Toronto in 2015. (For a selection of previously published papers of the Florence conference, see Koritar, 2018a, b) Authors representing different viewpoints joined in a whirlwind of bi-partisan discourse in the caesura between often polar opposite perspectives. The joining of thesis and antithesis gives birth to synthesis. The conceptual mingled with the empirical gives rise to transcendental thought. Various polarities intermingled: Freud/Ferenczi, intrapsychic/interpersonal, Darwin/Lamarck, phylogenetic/environmental, past/present, life/death, being/nothingness, virtual/analogical, experiential/conceptual, this-or-that/this-and-that. Binaries that are entrenched in

Endre Koritar, M. D. FRCP(C); FIPA; Guest Editor of this Special Issue; Assistant Clinical Professor, University of British Columbia, Canada; member of the Board of Directors of the International Sándor Ferenczi Network; Associate Editor, American Journal of Psychoanalysis; Training and Supervising Analyst, Western Psychoanalytic Society Institute.

Address correspondence to: Endre Koritar, M.D., 530-999 West Broadway, Vancouver, BC, Canada, V5Z $1 \mathrm{~K} 5$. 
their positions attempt to elide their counterpart. It is only in the turbulence of the caesura, the gap between the polarities, that compromise and bipartisan resolution is possible.

Many of the papers herein take up the debate of these binaries giving us insight into their synthesis.

Borgogno (2019) revisits the Freud/Ferenczi duality, which, after Ferenczi's death in 1933, resulted in the fifty-year-silencing of Ferenczian thought. The partisan culture of those years demanded choosing sides, and warring with the enemy. The Ferenczian vision of psychoanalysis was deemed heretical and unorthodox to the Freudian vision, resulting in his ostracism from the Freudian fold of orthodox classical analysts of the inner circle, and the proscription of his ideas in the training of future generations of analysts. Borgogno reviews several of Ferenczi's key concepts in a belated restoration to his rightful place as one of the key thinkers in establishing psychoanalytic theory and praxis in its contemporary form. Ferenczi had already formulated his own original theory of psychopathology prior to his meeting Freud, as is evident in his discussion in "The Effect on Women of Premature Ejaculation in Men" (Ferenczi, 1908). The absence of a loving concern for the other in the premature ejaculator, is at the root of repressed libido and hysterical symptoms in the woman. Ferenczi clearly places the source of pathology in the intersubjective field in contrast to Freud, who viewed psychopathology from the metapsychological perspective of phylogenetic drive management. Drives are precipitated in the relational situation in the former's vision, while they have a biological heritage in the latter's. Like Lamarck before him, Ferenczi considered that environmental pressures impact the development of the individual's characteristics (see Correspondence of Freud-Ferenczi, 1914-1919). Ferenczi elaborated his vision of ego development in "Introjection and Transference" (1909): the ego grows and expands by introjecting significant external objects. Ferenczi was swayed by Freud's elegant theorizing and his metapsychogical model of the mind, and experimented with active technique, collaborating with Freud in a fruitful interchange of correspondence, which fueled their mutual creative geniuses. Their visions for a psychoanalytic theory and praxis began to diverge after the publication of The Development of Psychoanalysis in 1924 (Ferenczi \& Rank). Ferenczi viewed that the healing process in analysis was linked to a repetition of past trauma in the analysis experienced by both analysand and analyst, but having a different outcome with a benevolent other, who is also working through the analysand's trauma, having introjected the other's experience in the countertransference. Working through the repressed trauma is contingent on a replaying of past conflictual scenarios, which resurface in the analysis. Freud, on the other hand, saw repetition compulsion as 
problematic and contributing to resistance in the analysis. In his view of analysis, making the unconscious conscious, and the ensuing insight would result in a freeing up of repressed creative energy, and a dissipation of pathological symptoms. In Ferenczi's view, a genuine and honest sympathetic attitude to the patient's suffering helps to heal the damaged self. For Freud, the application of standard analytic technique leads to selfawareness and a healthy ego. In the early days of analysis, the clinician had to choose this-or-that. In the contemporary scene, it is more accepted to integrate aspects of both the Freudian and Ferenczian points of view.

Coelho Junior (2019) defines different matrices in psychoanalytic theory and practice integrating them in a "transmatricicial" model. In the Freud/ Klenian matrix, analytic work is directed at interpreting resistances and inhibitions of free-flowing psychic energies. In this model, healing is contingent upon gaining insight into unconscious phantasy and making the unconscious conscious. The Ferenczian matrix, on the other hand, considers that as a result of early trauma, aspects of the self are shut down and deadened. Healing in this paradigm is contingent upon joining with the analysand's experience in the third space and facilitating the dreaming of their unlived life, in the process bringing to life deadened aspects of the self. Coelho Junior traces the development of thinking in the Ferenczian matrix from Winnicott (False Self/True Self), Bion (Container/Contained), Searles (the transference/countertransference relationship), Langs (the Bipersonal Field), the Barangers (Field Theory), and Ogden (The Third Space, Unlived Life). Whereas in the former matrix, dispassionate observation is the technical approach, in a transmatricial synthesis the therapist takes on a participant observer role, being and experiencing with the analysand, but then stepping back and observing that experience in the third space. The analyst's analysis of the experience in the third space then facilitates the analysand's dreaming and living an as yet unlived life.

Kelley-Lainé (2019) emphasizes the importance of creating an intimate space in the analysis that facilitates the emergence of a narrative which had previously been foreclosed. Stories frozen in a winter of the soul, thaw out in the summery warmth of the presence of an attentive analyst, allowing the stunted child in the adult, frozen in its development, to fully mature and become open to the creative possibilities the world has to offer. But to thaw out frozen parts of the self, the analyst needs to mutually experience the analysand's trauma. Kelley-Lainé shares her own story of a frozen child within. In writing on Barrie's Peter Pan, she outlines how putting her own story into narrative form helped her own frozen child thaw out and continue developing. This in turn facilitated movement in the analysis with her 
patient. She encourages writing about one's own narrative as a therapeutic activity, the reader serving as one's muse/analyst.

Koritar (2019) worked in the life/death, past/present dualities with a patient alienated from others, in a solipsistic existence. Struggling in a deadening, intellectualized analysis, Koritar became active and lively in searching for an oasis of meaning in the desert of the analysis. The rains came and the desert began to bloom when, after a comment about his mother, his patient passionately retorted: "I had no mother! The street was my mother!" This was followed by an enactment: re-visiting his birth home, where the foreclosed narrative of an unwelcome child surfaced. This lost story was forgotten by the patient soon after hearing it, but his wife, an observing third, was there and registered the details of a gripping and tragic tale of three generations of unwelcome children. It was not until later, as it gradually came up in analysis, with another third, that his wife was able to assist by confirming the details as they arose. The intersubjective space created by patient, analyst, and wife served as the exit point of his psychic retreat as an unwelcome child. He left the cave of his illusory ideologies and entered into the light of real object relatedness. The binaries life and death parallel the Heideggerian dialectic Being and Nothingness the synthesis of which is Becoming. He left his cave in becoming a significant other to others. The binary past/present played itself out as phantoms buried transgenerationally came out of their crypts and ceased to haunt him. He began to feel that he belonged and was wanted. Koritar's discussion of transgenerational transmission of trauma is interesting. Introjection of an object also means introjection of that object's internal objects where phantoms of past unresolved trauma dwell in crypts of the self. Resolution of transgenerational trauma would then be considered as a primary prevention of transmitting phantoms to future generations. The results of a successful analysis then reverberate down the corridors of time, ceasing to inflict one's progeny with one's own phantoms.

This type of active use of the analyst's countertransference situation whether reverie, experiencing the other's introjects, or, enactments, is also demonstrated in Ciacci's (2019) work in analyzing his countertransference. He provides the reader with a detailed account of the unfolding intersubjective interaction in the therapeutic space where he experienced his patient's internal object relations and used insight gained from analyzing this introjection disclosing her countertransference experience in his interpretations. Working with the actual experiences engendered by unconscious communication between the analytic couple is a much more 
vital form of therapy and the connection made with the patient provides a healing experience in the analytic space.

Hristeva (2019) offers a profound reflection on the mechanism of healing in the analytic process based on Ferenczi's views on Orpha and the Orphic analyst. In this scholarly paper, Hristeva provides a mythical allegory in Orpheus, to represent the psychoanalytic project. The Orpheus myth sets the stage on which binaries of descent/ascent, disintegration/reintegration, death/rebirth are discussed as milestones on the road to healing. In her considering Ferenczi as an Orphic analyst she redefines Ferenczi as an artist and poet using his craft to heal damaged souls. In the descent/ascent paradigm, the analyst has to descend into the dark abyss of the Underworld and search for the banished Euridyce. In the process, he is exposed to many dreadful experiences until he finally finds her but when called by name she responds "who?" Undeterred, Orpheus leads Euridyce out of Hades only to have her disappear back into the darkness once again, when he makes a wrong move. How much like therapy this scenario echoes! A persistent determination is demanded of the analyst accompanying a damaged spirit on the road back to health. This is a road with many hazards and obstacles. It is in the antimony of descent and ascent repeatedly experienced that a working out of the phantoms of trauma past leads to healing. The analyst must have the patience of a mother who weathers the storms of a frustrated child lashing out repeatedly at a mother perceived as a persecutor.

In the disintegration/reintegration paradigm, Orpheus plays his divine music restoring harmony to an inner world torn apart by catastrophic traumatic forces. The soothing voice of Ferenczi, the poet of the soul, with the soul of a poet, adds a salve to the fragmented spirit helping to restore harmony in the analysand's stormy internal world. The analysand's Guardian Angel, his Orpha, initially resorts to anesthesia, drug use, selfharm, even psychosis, in an attempt to manage the consequences of annihilation of the ego and potential psychic death. But Orpha will ideally lead the damaged spirit to seek an Orphic analyst with whom he can make the arduous ascent out of Hades.

While Hristeva offers the reader a lyrical mythos of healing in a relational context, Mucci (2019) grounds the reader in hard core research in neuroscience and attachment theory underlying the relational origins of psychopathology and its healing through the benevolent impact of an other who accepts the reality of the trauma. Mucci takes to task those who remain silent or in fact actively ignore the reality of physical, sexual, and emotional abuse. She cites the absence of Complex PTSD in the Diagnostic and Statistical Manual of Mental Disorders, the DSM 5, as evidence of a social scotoma in acknowledging the existence, especially in adolescents, of actual abuse and its PTSD aftermath. In her scholarly research into the 
brain/mind connection, Mucci provides the psychotherapy-informed reader a background in cutting edge neuroscience and attachment research, suggesting a model for understanding the healing process in therapy in terms of neuronal and epigenetic dynamics. Starting from neuroscience research in mentalization, and moving to the therapist as witness, she outlines a dynamic theory of internal object relations introducing a benevolent internal object which theoretically will impact the development of new neural pathways in the limbic system modulating unstable pathways initiated through environmental trauma. She also offers the intriguing idea that environmental impact on the genome, through epigenesis can be reversed through an "embodied witnessing" therapist, acknowledging the reality of the trauma. While intriguing ideas, these speculations would need further neuroscience research to confirm their validity. Nevertheless, Ferenczi's type of theorizing and practice are much more amenable to neuroscience research than the more metapsychological Freudian system. The relational paradigm has generated much more promising research to date likely since the environmental impact of relatedness results in neural events which can be measured instrumentally.

Juhos and Mészáros (2019) present a timely and elegant paper researching the pros and cons of remote analysis and supervision. They point out that a new generation of therapists are growing up in an era where information technology has transformed ways and means of communicating across distances. The practice of conducting therapy via the internet is becoming more frequent. Research, such as that conducted by Juhos and Mészáros is important so that clinicians can consider the impact that remote, internet-based communication has on the therapeutic process. The duality in question is between conventional, face-to-face (analog) and remote, internet based tele-therapy (virtual) therapy. In what way is virtual different from analog? Are there specific indications or contraindications? How does virtual versus analog impact the process of the transference/countertransference? These are important questions to consider in this new frontier. Their incisive review of the parameters of virtual communication offers important insight concerning the technical process and its potential impact on the therapeutic process. In his presentation of the clinical case, Juhos provides us with convincing evidence that an analytic process was engaged, and unconscious communication occurs even at a distance. The quality of the analytic work and insight into the transference and countertransference leaves the reader believing that remote analysis can be an option to in-the-room analysis. While the description of the benefit of this type of analytic work is convincing, Juhos and Mészáros offer cautionary advice in selecting suitable candidates for remote therapy. A thorough in-the-room initial assessment, the establishment of a therapeutic 
alliance, and the presence of an adequate support network are essential elements in cases where the regression induced by intense therapy might lead to setbacks in the patient's condition. The paper also presents the reader with insight into the supervisor/supervisee dynamics that weaves together seamlessly with the clinical material. I congratulate Juhos and Mészáros for providing the readers with not only an excellent review of remote therapy but also, insight into the third space dynamics of supervisor and supervisee that is rarely seen in the literature.

Ritter (2019) weaves together in an interesting synthesis, the history of the acceptance of Hungary's Jewish population into mainstream Hungarian society and culture, then dovetails it with the dynamics of extreme social persecution in the 20th century. In the process, Ritter is working out her own phantoms in the dilemmas of belonging vs. alienation and staying vs. leaving. Hungarian Jews suffered a profound blow to their sense of belonging to the Hungarian nation when in 1944, the murderous Arrow Cross Party colluded with Eichmann to deport and murder the entire Hungarian Jewish population (Braham, 2000). The Holocaust survivors' perception quickly shifted from a sense that they had finally found a place where they felt accepted as part of a nation and not outsiders, to disillusionment, being actively persecuted and once again, searching for a homeland. The sense of being outsiders is trans-generationally handed down, as is the trauma of being actively persecuted and cast out. Many survivors left for elsewhere, facing the challenges of departure and starting all over again. Yet staying in the place where the persecution and catastrophe occurred was also traumatic, as there were constant reminders and triggers to painful flashbacks in the "homeland". Ritter studies the outcome of those who fled Hungary after the war and arrives at an interesting conclusion. The émigrés often flourished in their new homeland as had the many Hungarian analysts who fled the Nazis in the 1930s, and in establishing themselves in the U.K., France, USA, and elsewhere, served as seeds for the dispersal of psychoanalytic theory and practice contributing to the growth of the local societies. They led creative lives and flourished, having turned their backs on the past, their gaze cast forward. This may well be a lesson for the current international situation where refugees from various world "hot spots" have caused mass migration to more developed countries. Emigrants continue to enrich the culture and economy of the host country which can lead to intellectual and economic growth. In the binary of staying/leaving Ritter firmly places herself "on the road". But in the process of working out her phantoms, she has given us insight into the internal situation of those who stayed and those who left. 
While all of the previous papers deal with secondary prevention of psychopathology, once environmental trauma has already had its impact, Vamos' (2019) intervention with parents of newborns has a modulating effect on the potential environmental trauma and, in effect, represents primary prevention of damage to the developing ego. She introduces the audience to the enlightened Avant-Garde maternity program called Les Bluets, in Paris. Inspired by Ferenczi's ideas on working with the child in the adult (Ferenczi, 1931), and focusing on his language of tenderness (Ferenczi, 1933), Vamos describes how a calm, containing, sympathetic attitude impacts anxious mothers and newborns, allowing the couple to develop the type of deep connection necessary for nurturing and growth of both mother and infant. Such a loving attitude modulates potential psychological damage to an unwelcome child who may develop a death drive, into becoming a loved child, vital in its life drive (Ferenczi, 1929). Such programs as Les Bluets should become widespread health policy aimed at defusing the death drive and psychopathology in adults later in life.

Social science researchers are increasingly turning to psychoanalytic theories in the analysis of social and political phenomena and trends. This represents another domain to which psychoanalysis can be applied: the analysis of society. While using dynamic principles and theories in analyzing the observed phenomenon or trend, social science researchers have a different conceptual framework with their own deep rooted traditions and tenets. In this tradition, Samir Gandesha (2019) has written a scholarly work analyzing the authoritarian personality in the context of the current resurgence of far right and far left political and social movements. He applies the dynamic theory of identification with the aggressor as elaborated by Ferenczi (1933) and the Budapest School, to Adorno's perspective of the authoritarian personality. In this hybrid social science and psychoanalysis theory, the individual experiences a fragmentation and diffusion of self and identifies with the ideology of the authoritarian leader; there is an extreme compliance to the will of the leader and individual moral values are elided; there is an intolerance of any form of critique and a disavowal of any debate of their version of reality. In this paper the far right and far left is viewed through the dynamic of identification with the aggressor. Far left students, positioning themselves against the authoritarianism of right wing conservative leaders, themselves act authoritarian, actively oppressing any critique of their ideology. These represent binaries intolerant of the existence of their polar opposite and seek to defeat each other.

The open spirit of the Florence Conference welcomed a wide range of contributors from diverse backgrounds. Presenters and participants shared a 
thinking space where new ideas were dreamt. Echo and feedback stimulated a debate of binaries: point and counterpoint, thesis and antithesis, and the back and forth of the empirical and the conceptual. The type of dreaming space facilitated by the Ferenczi in Firenze Conference encouraged dreamers to continue dreaming and recounting their dreams to others.

\section{NOTE}

1. Endre Koritar, M. D. FRCP $(C)$ is an Assistant Clinical Professor, University of British Columbia; Full member of the International Psychoanalytical Association, sits on the Board of Directors of the International Sándor Ferenczi Network, is an Associate Editor of the American Journal of Psychoanalysis, and a Training and Supervising Analyst, Western Psychoanalytic Society Institute.

\section{REFERENCES}

Borgogno, F. (2019). Sándor Ferenczi, a classical and contemporary psychoanalyst (with particular reference to transference and countertransference). American Journal of Psychoanalysis. https://doi.org/10.1057/s11231-019-09222-1.

Braham, R. L. (2000). Politics of genocide: The holocaust in Hungary. Detroit: Wayne State University Press.

Ciacci, A. (2019). Hidden voices: Emotional experience and unconscious communication in the analytic space. American Journal of Psychoanalysis. https://doi. org/10.1057/s11231-019-09217-y.

Coelho Junior N. E. (2019). From Ogden to Ferenczi-The constitution of a contemporary clinical thought. American Journal of Psychoanalysis. https://doi. org/10.1057/s11231-019-09218-x.

Ferenczi, S. (1908). The effect on women of the premature ejaculation of men. In Final contributions to the problems and methods of psychoanalysis (pp. 291-294). New York: Brunner/Mazel. (1980).

Ferenczi, S. (1909). Introjection and transference. In First contributions to psychoanalysis (pp. 35-93). New York: Brunner/Mazel. 1980.

Ferenczi, S. (1929). The unwelcome child and his death instinct. In Final contributions to the problems and methods of psychoanalysis (pp. 102-106). London: Karnac Books. 1994.

Ferenczi, S. (1931). Child-analysis in the analysis of the adults. In Final contributions to the problems and methods of psychoanalysis (pp. 126-142). London: Karnac Books. 1994.

Ferenczi, S. (1933). Confusion of tongues between adults and the child. The language of tenderness and of passion. In Final contribution to the problems and methods of psychoanalysis (pp. 156-167). London: Karnac Books. 1994. Also in International Journal of Psychoanalysis, 30, 225-230, published in 1949. 
Ferenczi, S., \& Rank, O. (1924). In G. H. Pollock (Ed.), The development of psychoanalysis (C. Newton, Trans.). Madison, Conn.: International Universities Press. 1986.

Freud, S., \& Ferenczi, S. (1914-1919). The correspondence for Sigmund Freud and Sándor Ferenczi, volume 2. 1914-1919. In E. Falzeder \& E. Brabant (Eds.), With an introduction by A. Hoffer (P. T. Hoffer, Trans.). Cambridge, MA: The Belknap Press of Harvard University Press. 1996.

Gandesha, S. (2019). The "Authoritarian Personality" reconsidered: The phantom of "left fascism". American Journal of Psychoanalysis. https://doi.org/10.1057/ s11231-019-09227-w.

Hristeva, G. (2019). "Primordial Chant". Sandor Ferenczi as an Orphic poet. American Journal of Psychoanalysis. https://doi.org/10.1057/s11231-019-09219w.

Juhos, C., \& Mészáros, J. (2019). Psychoanalytic psychotherapy and its supervision via videoconference: Experience, questions, and dilemmas. American Journal of Psychoanalysis. https://doi.org/10.1057/s11231-019-09220-3.

Kelley-Lainé, K. (2019). Constructing intimate space through narration: Ferenczi's Clinical Diary. American Journal of Psychoanalysis. https://doi.org/10.1057/ s11231-019-09221-2.

Koritar, E. (Ed.) (2018a). First special issue: Ferenczi in our time and a renaissance of psychoanalysis. Florence International Sándor Ferenczi Conference. American Journal of Psychoanalysis, 78(4).

Koritar, E. (2018b). Introduction. First Florence Ferenczi special issue. American Journal of Psychoanalysis, 78(4), 331-341.

Koritar, E. (2019). Working out phantoms in trans-generational transmission of trauma. American Journal of Psychoanalysis. https://doi.org/10.1057/s11231019-09226-х.

Mucci, C. (2019). Traumatization through human agency: "embodied witnessing" is essential in the treatment of survivors. American Journal of Psychoanalysis. https://doi.org/10.1057/s11231-019-09225-y.

Ritter, A. (2019). Escape from traumas: Emigration and Hungarian Jewish identity after the Holocaust. American Journal of Psychoanalysis. https://doi.org/10.1057/ s11231-019-09223-0.

Vamos, J. (2019). A primal environment for a 21 st century's, "naissance". Thoughts on the language of tenderness in Ferenczi's footsteps. American Journal of Psychoanalysis. https://doi.org/10.1057/s11231-019-09224-z.

Publisher's Note Springer Nature remains neutral with regard to jurisdictional claims in published maps and institutional affiliations. 